\title{
FORMAÇÃO EM PSICOLOGIA: O PROCESSO HISTÓRICO E A ANÁLISE DE UM PROJETO POLÍTICO PEDAGÓGICO
}

\author{
TRAINING IN PSYCHOLOGY: THE HISTORICAL PROCESS AND ANALYSIS OF A \\ PEDAGOGICAL POLITICAL PROJECT
}

\author{
Nauristela Ferreira Paniago Damasceno ${ }^{1}$ \\ Natália Müller ${ }^{2}$ \\ Maria José de Jesus Alves Cordeiro ${ }^{3}$ \\ Lourdes Missio ${ }^{4}$ \\ Cássia Barbosa Reis ${ }^{5}$ \\ Cibele de Moura Sales ${ }^{6}$
}

\begin{abstract}
Resumo
Este artigo discute a formação em Psicologia a partir dos principais processos históricos relacionados à regulamentação da profissão e das Diretrizes Curriculares Nacionais (2011). Procurou-se também analisar o Projeto Político Pedagógico PPP do curso de graduação de uma universidade pública, em relação à conformidade com as Diretrizes. Trata-se de uma pesquisa bibliográfica exploratória fundamentada em algumas produções sobre a história da Psicologia, normas que regulamentam a profissão, Resoluções e Pareceres do Conselho Nacional de Educação e revisão bibliográfica referente ao campo do currículo. Como resultado se percebeu que as Diretrizes possibilitaram avanços na formação e que é preciso avaliar se os novos PPP estão contribuindo, efetivamente, para formação de psicólogos capazes de analisar e intervir sobre a realidade nos vários contextos de atuação. Em relação ao
\end{abstract}

\footnotetext{
${ }^{1}$ Psicóloga, mestranda do Programa de Pós-graduação Stricto Sensu Ensino em Saúde, Mestrado Profissional (PPGES) da Universidade Estadual de Mato Grosso do Sul (UEMS). E-mail: naurapsi@ hotmail.com

2 Mestranda do Programa de Pós-graduação Stricto Sensu Ensino em Saúde, Mestrado Profissional (PPGES). Email: nat_muller@hotmail.com

${ }^{3}$ Doutora em Educação - Currículo pela Pontifícia Universidade Católica de São Paulo (PUC/SP. Atualmente é professora adjunta da Universidade Estadual de Mato Grosso do Sul (UEMS), docente do Mestrado em Educação e do Programa de Pós-graduação Stricto Sensu Ensino em Saúde, Mestrado Profissional (PPGES). Email: maju@uems.br

${ }^{4}$ Doutora em Educação pela Universidade Estadual de Campinas (UNICAMP). Atualmente é professora efetiva da Universidade Estadual de Mato Grosso do Sul (UEMS) e docente do Programa de Pós-graduação Stricto Sensu Ensino em Saúde, Mestrado Profissional (PPGES). E-mail: lourdesmissio@uems.br

${ }^{5}$ Doutora em Doenças Infecciosas e Parasitárias pela Universidade Federal de Mato Grosso do Sul. Atualmente é professora efetiva da Universidade Estadual de Mato Grosso do Sul (UEMS) e docente do Programa de Pósgraduação Stricto Sensu Ensino em Saúde, Mestrado Profissional (PPGES). E-mail: cassia@uems.br

${ }^{6}$ Doutora em Ciências da Saúde pela UNB. Atualmente é professora efetiva da Universidade Estadual de Mato Grosso do Sul (UEMS) e docente do Programa de Pós-graduação Stricto Sensu Ensino em Saúde, Mestrado Profissional (PPGES). E-mail: cibele_saless@ @icloud.com
} 
PPP analisado, o mesmo organiza-se formalmente de acordo com o estabelecido nas Diretrizes, embora permaneçam pontos contraditórios que podem indicar dificuldades para concretizá-lo.

Palavras-chave: Currículo. Projeto Político Pedagógico. Diretrizes Curriculares Nacionais. Formação em Psicologia.

\begin{abstract}
This paper discusses the training in Psychology from the main historical processes related to the regulation of the profession and the National Curriculum Guidelines (2011). It also sought to analyze the Pedagogical Political Project of the Psychology Graduate (PPP) of a Brazilian public university for compliance with the Guidelines. This bibliographic research used as investigation some sources productions about the history of psychology, laws and regulations of the profession and bibliography review about the field of curriculum. As a result it was noticed that the Guidelines have enabled advances in training and what it takes to assess whether the new PPP are contributing effectively to training psychologists able to analyze and intervene on reality in the various contexts of action. Regarding the analyzed PPP, it is organized formally in accordance with the provisions in the Guidelines, although they remain contradictory points that may indicate difficulties in achieving it.
\end{abstract}

Keywords: Curriculum. Pedagogical Political Project. Curriculum Guidelines. Training in Psychology.

\title{
INTRODUÇÃO
}

O objetivo deste artigo é discutir a formação em Psicologia, no Brasil, a partir dos principais processos históricos relacionados à regulamentação da profissão e das Diretrizes Curriculares Nacionais-DCN para os cursos de graduação em Psicologia. Considerando o campo do currículo, buscou-se ainda analisar o Projeto Político Pedagógico PPP do curso de graduação em Psicologia de uma universidade pública da região centro-oeste brasileira, em relação a sua conformidade com as DCN.

Realizou-se uma pesquisa bibliográfica exploratória com base em algumas produções sobre a história da Psicologia, nas normas que regulamentam a profissão, nas Resoluções e nos Pareceres do Conselho Nacional de Educação. A pesquisa fundamentou-se ainda no currículo como "[...] um projeto seletivo de cultura, cultural, social, política e administrativamente condicionado, que preenche a atividade escolar e que se torna realidade dentro das condições da escola tal como se acha configurada" e que "[...] modela-se dentro de um sistema escolar concreto, dirige-se a determinados professores e alunos, serve-se de 
Formação em psicologia: o processo histórico e a análise de um projeto político pedagógico

determinados meios, cristaliza, enfim, num contexto, que é o que acaba por lhe dar o significado real”. (SACRISTÁN, 2000, p. 34 e 21).

\section{PERCURSO DA PSICOLOGIA ATÉ SUA REGULAMENTAÇÃO}

Na literatura sobre o início da Psicologia no Brasil, alguns autores (PEREIRA; PEREIRA NETO, 2003; Conselho Regional de Psicologia de São Paulo, 2011; VILELA, 2012;) - remetem ao Brasil Colonial, período em que, principalmente, os jesuítas foram as influências mais marcantes na transmissão de saberes que hoje consideramos psicológicos, como as emoções, a educação, a aprendizagem, o autoconhecimento, o controle do comportamento e, a partir do século XVIII, a saúde através das práticas médicas (CONSELHO REGIONAL DE PSICOLOGIA DE SÃO PAULO, 2011). Nesse período, o discurso religioso voltava-se para a alma e os conhecimentos psicológicos estavam relacionados à Teologia, Filosofia, Pedagogia, Medicina e a Política.

A presença da corte portuguesa no Brasil (1808) e depois a independência (1822) influenciaram mudanças significativas na economia, na cultura e na sociedade brasileira. A criação de instituições de ensino, bibliotecas, sociedades científicas e periódicos na área de saúde são exemplos dessas mudanças (PEREIRA; PEREIRA NETO, 2003). De acordo com Vilela (2012) em um ambiente politicamente instável, além das ideias libertárias, ocorre divulgação do conhecimento científico, principalmente por médicos brasileiros que frequentaram cursos na Europa os quais também importaram os saberes da psicologia científica - em pleno desenvolvimento, na Europa, a partir do final do século XIX inserindo-os em suas teses. Dessa forma, segundo a autora, o discurso sobre o homem, anteriormente centrado na alma (psicologia filosófica), alterna-se para o organismo (psicologia científica).

Esses conhecimentos psicológicos, incorporados pelos médicos brasileiros, seriam aplicados nos hospícios criados a partir de 1840, para diagnóstico e tratamento de alucinações, epilepsia, histeria (Conselho Regional de Psicologia de São Paulo, 2011). Segundo Massimi (1990, p. 69) além das Faculdades de Medicina esse conhecimento foi difundido na Faculdade de Direito de São Paulo, nas Escolas Normais, nos seminários episcopais e nas escolas de formação religiosa. As Escolas Normais tiveram importante papel na introdução da psicologia na grade curricular dos cursos e na introdução da psicologia experimental que "parece 
oferecer à pedagogia o método objetivo para o conhecimento do homem e de seu processo evolutivo, substituindo-se ao método empírico ou filosófico da tradição anterior”.

Internacionalmente, no final do século XIX a psicologia já estava caminhando para uma aproximação das ciências naturais, através da investigação dos fenômenos sensoriais como forma de descrever detalhadamente os processos da consciência humana e de medir fatores básicos do comportamento dos indivíduos (PEREIRA; PEREIRA NETO, 2003). Nesse contexto, segundo Lisboa e Barbosa (2009), em 1893 a disciplina Psicologia torna-se obrigatória na Escola Normal de São Paulo e são criados os primeiros laboratórios de psicologia experimental das Escolas Normais e de alguns hospícios (CONSELHO REGIONAL DE PSICOLOGIA DE SÃO PAULO, 2011). O Pedagogium, um museu pedagógico, foi criado em 1890 no Rio de Janeiro e passou a funcionar como laboratório de psicologia experimental em 1906 (MASSIMI, 1990). Essa autora relata que em São Paulo iniciativas semelhantes ocorreram a partir de 1909, também nas escolas normais.

O projeto de curso de Psicologia construído em 1932 por Waclaw Radecki, diretor do antigo Laboratório de Psicologia do Hospital do Engenho de Dentro (RJ), é referido por Bernardes (2003) como o primeiro documento público sobre formação em Psicologia. Segundo Massimi (1990), em 1932, o laboratório foi transformado no Instituto de Psicologia da Secretaria de Estado de Educação e Saúde Pública, onde deveria ser organizado o primeiro curso de psicologia, para o qual Radecki coordenou a elaboração do projeto. A autora relata que o instituto sobreviveu apenas poucos meses, provavelmente devido à falta de recursos, e alguns anos depois, foi incorporado à Universidade do Brasil, atual Universidade Federal do Rio de Janeiro- UFRJ.

Segundo Pereira e Pereira Neto (2003) esse laboratório consolida o interesse da medicina pela psicologia e, citando Penna (1992), os autores apontam que entre as atividades desenvolvidas no laboratório, além da psicologia experimental, eram realizadas testagens e psicoterapia, as quais, mais tarde, viriam caracterizar fortemente a atividade do psicólogo.

Nota-se, pelo exposto, o papel de destaque da educação (através das Escolas Normais) e da medicina (através a psiquiatria) na institucionalização da psicologia; entretanto, o foco não era a autonomia e a profissionalização, visto que ela estava submetida aos interesses de outras profissões. (PEREIRA; PEREIRA NETO, 2003).

Com a criação da primeira universidade brasileira, a Universidade de São Paulo, em 1934, a psicologia integra-se ao ensino superior tornando-se obrigatória nos cursos de 
Formação em psicologia: o processo histórico e a análise de um projeto político pedagógico

Filosofia, Ciências Sociais e Pedagogia, além de se inserir nos cursos de licenciatura (LISBOA; BARBOSA, 2009). Segundo Pereira e Pereira Neto (2003), no Rio de Janeiro, na Universidade do Brasil, ocorre algo semelhante e, dessa forma, começam a proliferar as cátedras em psicologia.

Conforme aponta Soares (2010), duas legislações se destacam no que se refere à institucionalização da Psicologia: primeiro o Decreto-lei $n^{\circ}$ 9.092, de 26/03/1946 que estabelece a obrigatoriedade do curso de Psicologia Aplicada à Educação para a obtenção do diploma de licenciado; depois a Portaria n ${ }^{\circ}$ 272, de 13/04/1946, do Ministério de Educação e Saúde que regulamenta os diplomas de especialização, entre eles o de psicólogo. A partir desse período começam a atuar profissionalmente os psicólogos especialistas, ocupando o mercado de trabalho em vários setores - educação, trabalho (principalmente em processos de seleção) e clínica; entretanto, a formação ainda é difusa e superficial, com base em cursos de curta duração destinados aos graduados em outros cursos (LISBOA; BARBOSA, 2009). Segundo Vilela (2012), nesse período os testes psicológicos, representaram um instrumento privilegiado, que diferenciava o novo profissional, em todos os campos de atuação.

No início da década de 1950 são criados os dois primeiros cursos de graduação em Psicologia, no Rio de Janeiro e no Rio Grande do Sul, em universidades católicas. De acordo com Vilela (2012), nesse contexto em que os profissionais já estavam ocupando o mercado de trabalho, se organizavam em associações, publicavam em periódicos de psicologia e havia curso superior formando novos profissionais habilitados, começa-se a buscar a regulamentação da profissão e dos cursos.

Um importante passo nessa direção foi o pré-projeto de currículo elaborado pela Associação Brasileira de Psicotécnica, atualmente Associação Brasileira de Psicologia Aplicada, em 1954 para o Conselho Nacional de Educação (PEREIRA; PEREIRA NETO, 2003). A partir desse pré-projeto, como se observa na literatura (VILELA, 2012) e no Parecer $n^{\circ}$ 1.314, aprovado em 7/11/2001, do Conselho Nacional de Educação (BRASIL, 2001), sobre as Diretrizes Curriculares para o Curso de Graduação em Psicologia, vários atores participaram do debate que culminou na aprovação da Lei n ${ }^{\circ} 4.119$, de 27/08/62, que regulamentou a profissão de psicólogo e no Parecer no 403, aprovado em 19/12/1962, do Conselho Federal de Educação, que estabeleceu o currículo mínimo e a duração do curso superior de psicologia (Associação Brasileira de Ensino de Psicologia, s/d; VILELA, 2012). 
Outros marcos importantes para a regulamentação foram: a criação, em 1961, do curso de psicologia da Universidade Federal da Bahia, que teve sua primeira turma iniciando em 1969, o primeiro curso de mestrado em Psicologia, em 1966 na PUC do Rio de Janeiro; o primeiro curso de doutorado, na Universidade de São Paulo-USP em 1974 (FÉRESCARNEIRO, 2007); a criação dos Conselhos Federal e Regionais de Psicologia, através da Lei $\mathrm{n}^{\circ}$ 5.766, de 20/12/1971; e em 1975 o primeiro Código de Ética dos psicólogos (Resolução $n^{\circ}$ 8, de 02/02/1975, do Conselho Federal de Psicologia), o qual foi revisto em 1979, 1987 e 2005.

Em todo esse período, manteve-se o perfil de atuação da década de 1940 - nas áreas clínica, educação e trabalho - com forte tendência para a clínica, em consultórios particulares, como profissional liberal. Conforme defende Zurba (2011) isso decorre da associação da Psicologia, em sua origem, com o pensamento liberal, baseado no livre arbítrio do indivíduo a despeito das suas condições materiais de existência. Ainda segundo a autora, no Brasil, esse modelo era favorável ao momento de governabilidade nos anos da ditadura militar e foi um dificultador na inserção da Psicologia nas Políticas Públicas, o que começou a mudar apenas após a Constituição Federal de 1988, que criou o Sistema Único de Saúde - SUS, com o Estatuto da Criança e do Adolescente (ECA- Lei $\mathrm{n}^{\circ}$ 8.069, de 13/07/1990) e, mais efetivamente, com a criação de cargos para psicólogos em diferentes estratégias do SUS. Nas últimas décadas, além da saúde, outras áreas de atuação têm despontado: jurídica, trânsito, esporte. (PEREIRA; PEREIRA NETO, 2003).

A inserção do psicólogo em novos contextos do mercado de trabalho remete a novas necessidades no processo de sua formação. Os primeiros cursos, logo após a regulamentação, foram organizados a partir do currículo mínimo, em três níveis: bacharelado (com foco na pesquisa), licenciatura (centrado na docência) e formação de psicólogo (formação profissional); os dois primeiros com quatro anos de duração e o último com cinco anos. (LISBOA; BARBOSA, 2009).

Mais à frente, em 1996, com a promulgação da Lei $n^{\circ}$ 9.394, de 20/12/1996 - Lei de Diretrizes e Bases da Educação Nacional - LDB, o Ministério da Educação instituiu uma comissão de especialistas em ensino de Psicologia com finalidade de elaborar as diretrizes curriculares para a graduação em Psicologia, em substituição ao antigo currículo mínimo (YAMAMOTO, 2000). Segundo o Parecer CNE/CES 0062, aprovado em 19/02/2004, após debates com instituições de ensino superior e entidades profissionais, em 1999, a Comissão de 
especialistas apresentou uma minuta de resolução com as Diretrizes Curriculares Nacionais, a qual voltou a ser debatida devido às divergências relacionadas aos perfis do profissional da psicologia (bacharelado, licenciatura e formação de psicólogo).

O consenso foi estabelecido em fevereiro de 2004 e em março foram instituídas as Diretrizes Curriculares Nacionais para os cursos de graduação em Psicologia, através da Resolução CNE/CES nº 8, de 07/05/2004. Em 2009, de acordo o Parecer CNE/CES nº 338, aprovado em 12/11/2009, devido à falta de clareza sobre a formação de professores de Psicologia, apontou-se a necessidade de alteração do artigo 13 da Resolução CNE/CES no 8/2004, que tratava da questão. (BRASIL, 2009).

No entanto, considerou-se que o mais adequado seria reeditar as Diretrizes de 2004, na íntegra, com alteração apenas desse artigo e revogação da Resolução anterior. Dessa forma, em 2011 foi aprovada a Resolução CNE/CSE n 5, de 15/03/2011 que instituiu as DCN para os cursos de graduação em Psicologia e as normas para o projeto pedagógico complementar para a formação de professores de Psicologia. A partir da alteração realizada, a Formação de Professores de Psicologia constitui-se em um projeto pedagógico complementar e diferenciado. (BRASIL, 2011).

\section{AS DIRETRIZES CURRICULARES NACIONAIS PARA OS CURSOS DE GRADUAÇÃO EM PSICOLOGIA}

Do currículo mínimo - estabelecido pelo Parecer $n^{\circ} 403$ do Conselho Federal de Educação, aprovado em 19/12/1962 - às Diretrizes Curriculares Nacionais para os cursos de graduação em Psicologia, doravante designadas apenas DCNP, aprovadas em 2011, passaramse quase 50 anos de debates, conflitos, avanços e retrocessos na formação em Psicologia, entre os psicólogos dos diversos segmentos e também com outras profissões (PEREIRA; PEREIRA NETO, 2003). Esse percurso, conforme refere Bernardes (2012), marca um processo histórico e coletivo importante para a Psicologia brasileira e que faz parte do currículo, o qual, conforme ressalta Silva (2001) não se resume à grade de disciplinas, mas é:

[...] sempre uma imposição de sentidos, de valores, de saberes, de subjetividades particulares. É sempre uma escolha forçada, para nos valermos da força de um oximoro. Um currículo é o resultado final de um confronto de forças, de relações de poder. Um currículo não é apenas um local em que se desdobram relações de poder: um currículo encarna relações de poder. Todo currículo é pura relação de força. (SILVA, 2001, p. 14-15). 
De acordo com Bernardes (2012) o currículo mínimo baseava-se em teorias de aprendizagem formais, na transmissão de conhecimentos através do parcelamento de disciplinas e do processo de aprendizagem isolado do contexto social; já as DCNP, como refere o texto do artigo $2^{\circ}$, da Resolução 5/2011 (BRASIL, 2011), constituem as orientações sobre princípios, fundamentos, condições de oferecimento e procedimentos para o planejamento, implementação e avaliação do curso de Psicologia. Essas orientações, de uma forma geral, baseiam-se no perfil do profissional que se deseja formar e procuram indicar as competências e as habilidades necessárias para que o futuro profissional atenda ao perfil demandado.

Os princípios e os compromissos da formação profissional, voltada para a atuação profissional, pesquisa e ensino de Psicologia, são os seguintes: a) construção e desenvolvimento do conhecimento científico em Psicologia; b) compreensão dos múltiplos referenciais que buscam apreender a amplitude do fenômeno psicológico em suas interfaces com os fenômenos biológicos e sociais; c) reconhecimento da diversidade de perspectivas necessárias para compreensão do ser humano e incentivo à interlocução com campos de conhecimento que permitam a apreensão da complexidade e multideterminação do fenômeno psicológico; d) compreensão crítica dos fenômenos sociais, econômicos, culturais e políticos do País, fundamentais ao exercício da cidadania e da profissão; e) atuação em diferentes contextos considerando as necessidades sociais e os direitos humanos, tendo em vista a promoção da qualidade de vida dos indivíduos, grupos, organizações e comunidades; f) respeito à ética nas relações com clientes e usuários, com colegas, com o público e na produção e divulgação de pesquisas, trabalhos e informações na área da Psicologia; g) aprimoramento e capacitação contínuos. (BRASIL, 2011).

A partir da concepção de que a formação deve ser capaz de dotar o profissional dos conhecimentos requeridos para o exercício de algumas competências e habilidades gerais, são inseridas as seguintes: atenção à saúde, tomada de decisões, comunicação, liderança, administração e gerenciamento e educação permanente. Além disso, de acordo com as DCNP, a formação em Psicologia exige que o projeto político pedagógico do curso articule os conhecimentos, habilidades e competências em torno dos seguintes eixos estruturantes: fundamentos epistemológicos e históricos; fundamentos teórico-metodológicos; procedimentos para a investigação científica e a prática profissional; fenômenos e processos 
Formação em psicologia: o processo histórico e a análise de um projeto político pedagógico

psicológicos; interfaces com campos afins do conhecimento e práticas profissionais. (BRASIL, 2011).

Especificamente para a Formação de Professores em Psicologia, as DCNP indicam os seguintes eixos estruturantes específicos: Psicologia, Políticas Públicas e Educacionais; Psicologia e Instituições Educacionais; Filosofia, Psicologia e Educação; Disciplinaridade e interdisciplinaridade. (BRASIL, 2011).

Para garantir uma identidade nacional e uma formação básica nos cursos, as Diretrizes (BRASIL, 2011) instituem ainda um núcleo comum o qual estabelece uma base homogênea para a formação no País e uma capacitação básica para lidar com os conteúdos da Psicologia, enquanto campo de conhecimento e de atuação.

Considerando o proposto nas DCNP, encerra-se a concepção de áreas de atuação profissional durante a formação e as áreas tradicionais (clínica, escolar e trabalho) dão lugar às ênfases curriculares. As Instituições de Ensino Superior devem oferecer pelo menos duas ênfases assegurando, no projeto do curso, mecanismos que permitam ao aluno escolher uma ou mais dentre as ênfases propostas. O texto das DCNP traz algumas sugestões de ênfases: processos de investigação científica, processos educativos, processos de gestão, processos de prevenção e promoção de saúde, processos clínicos e processos de avaliação diagnóstica (BRASIL, 2011).

Segundo Bardagi et al. (2008) as DCNP, enquanto projeto de mudança, são uma ameaça às estruturas e feudos de muitos cursos, departamentos e universidades. Em contrapartida elas oferecem uma oportunidade de reforma e integração, garantindo simultaneamente a homogeneidade e a diversidade de formação, tendo as universidades o papel de fornecer, além de espaços de discussão sobre essas transformações, a oportunidade do desenvolvimento de competências relativas às mesmas.

As DCNP, para Bernardes (2012), são dispositivos tecnológicos produzidos a partir de certa racionalidade prática e caracterizam formas específicas de governo. Dessa forma, devese considerar que as ênfases, eixos, competências, habilidades indicam a forma como cada universidade organiza seu curso e representam o produto dos conflitos de relações de poder e de saberes, os quais também se refletem na forma como a prática é planejada e depois, de fato, realizada.

Abdalla, Batista e Batista (2008) afirmam que as DCNP mostram um novo caminho para a formação do profissional e propõem a integração de conteúdos e o desenvolvimento de 
competências e habilidades bem como a utilização de metodologias ativas de ensino que levem o estudante a aprender a aprender e a compreender a necessidade da educação permanente e a integração do ensino, dos serviços de saúde e da comunidade aproximando o futuro profissional da realidade social. Os autores também defendem que o incentivo à pesquisa, à extensão e à assistência contribui para a formação de profissionais com autonomia e discernimento para a integralidade do cuidado, a qualidade e humanização de suas práticas.

As DCNP também enfatizam outros aspectos considerados fundamentais no plano da formação profissional tais como a contextualização do fenômeno psíquico, a observação, a estruturação do ato pedagógico que possibilite a aquisição das competências e habilidades necessárias à atuação, a crítica teórico-metodológica, a inclusão de conteúdos advindos da Antropologia, da Filosofia e da Sociologia, o trabalho em equipes multiprofissionais e a relação universidade-comunidade. (BRASILEIRO; SOUZA, 2010).

No que tange às críticas às DCNP percebe-se no estudo de Brasileiro e Souza (2010), que os alunos se queixam da falta de conciliação entre teoria e prática e de dificuldades como a inserção da prática nas disciplinas do núcleo comum. Antes, boa parte dos cursos de Psicologia organizava os estágios curriculares em três áreas tradicionais e obrigatórias: clínica, escola e trabalho. Atualmente, boa parte desses cursos reduziu os estágios de três para dois, vinculados às ênfases introduzidas pelas Diretrizes. (BERNARDES, 2012).

Nesse mesmo contexto, para Bernardes (2012), a noção de ênfases curriculares é herdeira de certa racionalidade prática e reproduz, no contexto das reformas curriculares, a hegemonia histórica da Psicologia Aplicada, sendo que um dos motores desse processo é a não diferenciação entre áreas de conhecimento, campos de atuação e objetos de estudo, que se encontram consolidados nas escolas, empresas e clínicas (consultórios, ambulatórios, hospitais). O autor menciona que:

Trocando em miúdos, é o clássico discurso comumente escutado nos cursos de que a Psicologia escolar por exemplo, é trabalhada em escolas e foca processos de ensinoaprendizagem, ou a Psicologia organizacional é trabalhada em empresas e foca seus estudos em processos e em relações de trabalho. Tudo o mais que compõe esses campos ou locais fica fora da atuação desse profissional, como se, nas escolas, não pudéssemos tratar de relações de trabalho, sofrimento, relações comunitárias, familiares, etc. Uma checagem rápida em instituições hospitalares, por exemplo, e verificamos claramente isso: os modos de atenção geralmente estão afastados dos modos de gestão. Os setores de recursos humanos possuem pouco ou nenhum diálogo com os setores clínicos e vice-versa. (BERNARDES, 2012, p. 222). 
Esse processo é corroborado pelo estudo de Bardagi et al. (2008) no qual há indicação de que 52\% dos egressos dos cursos de graduação em Psicologia da Universidade Federal do Rio Grande do Sul (UFRGS) nos anos de 1997 a 2004, não se sentiram preparados para a atuação profissional, considerando como fator importante a melhor articulação entre teoria e prática, bem como algumas mudanças curriculares. Esses pontos também são perceptíveis no estudo de Brasileiro e Souza (2010), que ouviu alunos, professores e coordenadores de um curso de graduação em Psicologia, conforme alguns relatos transcritos abaixo:

\begin{abstract}
Faltam às diretrizes indicações de como articular os conteúdos, as informações, na formação deste profissional (P1, 2009); Mediante a realidade de nossas universidades, principalmente a nossa, com um número reduzido de professores, colocarmos em prática essa diretriz não será fácil, porque supervisionar as atividades práticas previstas na diretriz vai ser um desafio (P2, 2009); Estamos pleiteando para que cada disciplina, cada setor, consiga realmente viabilizar, articular esse conhecimento teórico com a prática, promover ações específicas na formação de cada profissional, é o que a gente encontra no núcleo comum. (C, 2009). (BRASILEIRO; SOUZA, 2010, p. 116).
\end{abstract}

As DCNP focalizam a necessidade de o psicólogo atuar interdisciplinar e multiprofissionalmente, todavia as estratégias de aprendizagem e estruturação do cenário do trabalho mostram-se incipientes nos cursos de graduação (POPPE; BATISTA, 2012). Ainda assim, percebe-se que algumas Instituições de Ensino Superior (IES) têm essa preocupação e consideram as realidades culturais de cada região.

No que se refere às mudanças curriculares para melhor articulação entre teoria e prática, Bernardes (2012) declara que o primeiro desafio está vinculado à superação da ideia de que o currículo se reduz a uma lista ou a uma grade de disciplinas. Para o autor, currículo é muito mais que isso, pois é implementado no campo das relações de poder e na produção de cultura. O Conselho Federal de Psicologia (2013) também indica que essa pode não ser exatamente uma questão curricular, ao referir que não são as DCNP que deixam a desejar na integração teoria-prática e sim as próprias instituições de ensino superior, uma vez que

as diretrizes para a formação profissional têm um discurso que dialoga com a realidade, fundado em consolidadas justificativas e fundamentos teóricos; no entanto, muitas instituições de ensino superior não realizam o que está escrito em seu projeto político pedagógico. Uma coisa é o que dizem, outra coisa é o que concretizam no dia a dia nas salas de aula e espaços de formação. (CONSELHO FEDERAL DE PSICOLOGIA, 2013, p. 16).

No que se refere à saúde, um dos domínios ainda não consolidados de atuação profissional do psicólogo, Lopes e Lima (2012) relatam que a integração entre as instituições 
de ensino e as de saúde permite a aproximação do conhecimento teórico com a realidade prática e, com isso, possibilita o surgimento de novas estratégias para a manutenção e o aprimoramento dos serviços de saúde. Contudo, segundo as autoras, para que essa parceria contribua para a troca de experiências e conhecimentos, a universidade deve estar atenta ao acompanhamento do trabalho do estagiário, pois a dificuldade do sistema público de saúde pode facilitar o uso de "mão de obra barata" e o trabalho do estagiário não deve preencher lacunas e falhas do sistema.

Daltro et al. (2013) relataram que os estudantes com a experiência de formação em serviço desenvolvem conhecimentos diferenciados, retratados na possibilidade concreta do desenvolvimento contínuo das competências conceituais, procedimentais e atitudinais exigidas na atuação do psicólogo no contexto hospitalar, ressaltando a importância da prática em serviços, no desenvolvimento de habilidades e na oportunidade de conhecer a complexidade de se fazer psicólogo em diferentes realidades e práticas, além das tradicionalmente consolidadas na atuação profissional.

Lopes e Lima (2012), em uma pesquisa sobre as contribuições da pareceria entre hospitais e universidades na formação em Psicologia, concluíram que o aprendizado proporcionado pelo estágio foi um avanço na formação dos estudantes de graduação em Psicologia porque permitiu que, antes de sua efetiva inserção na área da saúde, já tivessem adquirido, minimamente, os recursos necessários para atuar a partir da análise do que se apresentava como necessidade de trabalho e das demandas, e não como mera transposição de modelos teóricos previamente aprendidos.

Nos estágios, o estudante é beneficiado ao apropriar-se da realidade prática até então não vivenciada e adquire experiência na área, enquanto o serviço de psicologia do hospital tem um aumento no número de pacientes atendidos e ainda pode contar com a possibilidade de atualizar seus conhecimentos na medida em que o aluno agrega novas ideias e percepções, possibilitando um repensar paradigmas e práticas de saúde. (LOPES; LIMA, 2012).

O diálogo da teoria com a prática e com a realidade é essencial para o desenvolvimento das habilidades e das competências demandas ao futuro profissional. Nesse sentido, o Conselho Federal de Psicologia (2013) também afirma que são várias as psicologias, mas ressalta que na verdade são formados profissionais sem clareza de qual será seu perfil de atuação, havendo aqueles que buscam - ou são levados a buscar, pelo mercado de trabalho - alternativas não muito tradicionais de atuação, como nos serviços públicos de 
Formação em psicologia: o processo histórico e a análise de um projeto político pedagógico

saúde, assistência social, educação pública, mas sentem-se ainda impotentes e despreparados para a atuação na realidade, uma vez que seu curso de formação não fez diferenciação para as demandas desses contextos de trabalho profissional, embora, desde 2004 as DCNP já apontem para esse caminho.

No contexto da atuação profissional em serviços de saúde pública, Ronzani e Rodrigues (2006) realizaram um estudo que aponta para o despreparo dos psicólogos em relação ao seu papel nos serviços de atenção básica, ao trabalho inter e multidisciplinar e para a necessidade de repensar a formação, visando preparar o futuro profissional para atuar em contextos de saúde que se diferenciam do modelo clínico do atendimento individual.

Ainda que consideremos os avanços realizados, conforme mencionam Ferreira Neto e Penna (2006), o texto das DCNP apresenta algumas referências paradoxais: despontam três linhas mestras enfatizando: o desenvolvimento científico da Psicologia, o reconhecimento da atual diversidade dos contextos de atuação profissional e o exercício da cidadania; por um lado, nos conteúdos curriculares fala-se em "fundamentos epistemológicos" e, na sequência, em "fundamentos metodológicos", sempre no plural; enquanto, nas habilidades, artigo $9^{\circ}$, inciso III, lê-se: "Utilizar os métodos experimental, de observação e outros métodos de investigação científica". (BRASIL, 2011, p. 3).

Dessa forma, como demonstram Ferreira Neto e Penna (2006), mesmo com a indicação para uma pluralidade no âmbito da epistemologia e da metodologia, o modelo de investigação das Ciências Naturais possui ainda um evidente privilégio e, a despeito da grande contribuição da Psicologia para as metodologias de pesquisas qualitativas, elas não são sequer mencionadas nas DCNP.

Pode-se supor que este privilégio dado a essa perspectiva de Ciência seja uma tentativa para que os parâmetros curriculares não sejam descritos como um dispositivo de produção de processos de subjetivação, uma vez que para as Ciências Naturais a subjetividade do psicólogo pesquisador é um obstáculo ao rigor metodológico. Com isso, entretanto, se desvaloriza a importância da contribuição que a clínica pode trazer para a formação geral do psicólogo, dissociando a prática clínica do núcleo essencial da formação. (FERREIRA NETO; PENNA, 2006).

Ferreira Netto e Penna (2006) ainda relatam que a presença da clínica na formação implica em "práticas de si" como pré-requisito para a atuação do psicólogo. Contudo, essa contribuição da clínica não foi incorporada nas DCNP. Nelas, prevalece a imagem do 
psicólogo cientista e cidadão, portador de competências e habilidades, mas sem a referência necessária ao trabalho ético sobre si que sua formação exigiria. Se no passado recente houve uma supervalorização da área clínica em detrimento de outras áreas de atuação importantes para o psicólogo, percebe-se, no contexto das DCNP, uma negligência com relação às importantes contribuições da clínica na formação geral.

Dentre as nove competências básicas e as sete habilidades requeridas na formação do psicólogo, de acordo com o texto das DCNP (BRASIL, 2011), há apenas uma que aborda esta questão, e, mesmo assim, de modo tangencial: a competência descrita no inciso X, do artigo $8^{\circ}$, "relacionar-se com o outro de modo a propiciar o desenvolvimento de vínculos interpessoais requeridos na sua atuação profissional" (BRASIL, 2011, p. 3). Nos demais itens o foco é instrumental referindo-se à importância de identificar, analisar, avaliar, levantar, planejar, interpretar, descrever, escolher/utilizar instrumentos. Mesmo no que se refere às práticas tão enfatizadas, as DCNP também não avançam, pois se limitam a remeter seus objetivos a garantir o "desenvolvimento das competências" específicas e exigir a instalação de um serviço de Psicologia. (FERREIRA NETO; PENNA, 2006).

\section{UM PROJETO POLÍTICO PEDAGÓGICO}

Considerando a trajetória da Psicologia até as DCNP aprovadas em 2011 analisa-se, em linhas gerais, o Projeto Político Pedagógico (PPP) do curso de graduação em Psicologia de uma das universidades públicas da região centro-oeste. A análise foi realizada com base no PPP disponibilizado no site da Instituição de Ensino Superior (IES) e acessado em maio de 2014.

O PPP é datado de 2011 e apresenta-se a partir da história da instituição, da história do curso e da necessidade social do mesmo na microrregião onde se localiza a IES, a qual congrega pouco mais de trinta municípios, compreendendo zona rural, urbana, quilombola e indígena. Destaca-se, nessa parte inicial, que o curso de Psicologia foi implantado em 2007, com outros nove cursos no contexto da adesão da Universidade ao Programa de Apoio ao Plano de Reestruturação e Expansão das Universidades Federais - REUNI. O primeiro processo seletivo ocorreu em 2009 e quanto à necessidade social do curso, para a região, são enfatizadas as alterações de demanda para o trabalho do psicólogo, principalmente nas áreas de saúde, trabalho e psicologia social. 
No que se refere aos aspectos formais de organização (carga horária, eixos, ênfases, núcleo comum, estágios básico e específico) o PPP apresenta-se em conformidade com o estabelecido na Resolução 5/2011.

O objetivo geral do curso, para o bacharelado e para a licenciatura, é formar um psicólogo comprometido com o conhecimento científico, com a ética e com a cidadania, considerando as demandas sociais e as diversidades humanas e sociais. O perfil esperado do egresso contempla ainda o comprometimento com o bem-estar do ser humano ao longo da vida e com a saúde da subjetividade.

A estrutura curricular organiza-se em bacharelado e formação de professores de Psicologia. A segunda ênfase se dá por meio de projeto complementar, sendo facultativa, ao aluno, cursá-la, conforme previsto nas DCNP. As disciplinas teórico-metodológicas distribuem-se em: obrigatórias, optativas, eletivas e atividades complementares e, de acordo com o PPP, o conhecimento da Psicologia é organizado em cinco ciclos, assegurando a interdisciplinaridade e contribuindo para a diminuição da fragmentação das ações desenvolvidas nos programas de aprendizagem. Os ciclos referidos são: formação humanística e fundamentos da ciência psicológica; Psicologia e as dimensões sociais e individuais do homem; aplicação da Psicologia em contextos sociais, comunitários e atuação do profissional de Psicologia; relações entre técnicas e práxis do psicólogo e do professor de psicologia, prática profissional do psicólogo aplicada às microrrealidades.

A prática é prevista desde o primeiro ano, através de atividades organizadas em estágios básicos no âmbito das disciplinas. Nos estágios curriculares, possibilita-se a vivência, sob supervisão, em diferentes campos de atuação profissional, os quais são discutidos entre alunos e professores, segundo o PPP. Atendendo ao previsto nas Diretrizes, a instituição oferece estágios supervisionados básicos (relacionados ao núcleo comum, envolvem etapas de observação, avaliação, planejamento e contato com a realidade social) e específicos (relacionados às ênfases do curso, em situações de atividade profissional, junto às escolas, empresas, hospitais e comunidade, sob orientação dos docentes e supervisão dos profissionais vinculados à instituição que recebe o estagiário), entretanto supera em mais de $3 \%$ a carga horária total exigida (15\%). Quanto à exigência expressa, nas DCNP, sobre a criação de um serviço de Psicologia, o mesmo é realizado em um laboratório anexo ao hospital universitário.

O curso possui duas ênfases: atenção em processos grupais e comunitários e subjetividades e a clínica contemporânea. Ambas se articulam com os conhecimentos, 
habilidades e competências descritas nas diretrizes e o PPP prevê uma discussão processual e integrada entre essas duas ênfases, combatendo a cisão tradicional das práticas psicológicas, o que é realizado através de quatro disciplinas optativas e também através dos estágios específicos, nos quais é garantido que o aluno possa optar por possibilidades de estágios nas duas ênfases. Como a articulação entre as ênfases é realizada através de disciplinas optativas e o estágio nessas duas ênfases também é opção do aluno, percebe-se que é o estudante quem direciona sua formação para os processos grupais, para a clínica, ou para ambos. Entretanto, esse direcionamento pode também ser influenciado pelo mercado de trabalho, pela formação dos professores do curso, entre outros fatores.

De acordo com o projeto a promoção da interdisciplinaridade ocorre por meio das disciplinas do eixo comum à Universidade, composto por 12 disciplinas, das quais o aluno deve eleger seis, matriculando-se em diferentes cursos oferecidos na instituição. Essas disciplinas dos eixos comuns à Universidade integram a proposta do REUNI no que se refere à promoção de interdisciplinaridade e mobilidade acadêmica.

O projeto contempla as várias áreas de atuação do psicólogo, o que está de acordo com as DCNP, inclusive rompendo com a hegemonia de áreas tradicionais, incluindo disciplinas e estágios que abordam: a área da saúde pública, hospitalar, jurídica, Psicologia comunitária. Nesse contexto, também se destacam disciplinas como: Libras, Campesinato (conjunto de agricultores de uma região) e Movimentos Sociais no Campo Brasileiro, Historiografia (da região onde se localiza o curso), Relações de gênero, Cultura e diversidade étnico-racial, Psicologia ambiental, Psicologia do esporte, Psicologia e arte, Psicologia jurídica, Psicologia comunitária, Psicologia hospitalar, Psicologia da terceira idade, entre outras; algumas dessas disciplinas remetem a questões sociais, culturais, econômicas e políticas relacionadas à microrregião onde localiza a instituição e/ou áreas não tradicionais da Psicologia.

Quanto aos processos de avaliação, o PPP contempla a avaliação da aprendizagem dos alunos - orientada pelo princípio metodológico de ação-reflexão-ação - e um sistema de autoavaliação do curso, o qual se divide em avaliação externa (Exame Nacional de Desempenho dos Estudantes e, indiretamente, pela sociedade que recebe os profissionais formados pela instituição) e interna (realizada periodicamente através de questionários direcionados aos alunos, professores e outros instrumentos de avaliação).

Nesse ponto, cabe ressaltar que não foi identificada a forma como seria realizada e aproveitada a avaliação da sociedade em que atuam os profissionais formados pela instituição, 
Formação em psicologia: o processo histórico e a análise de um projeto político pedagógico

bem como sobre a previsão de algum tipo de avaliação sobre a percepção desses profissionais quanto às contribuições da formação para sua atuação no mercado de trabalho e às oportunidades de melhoria para o curso. Quanto à avaliação interna, não foram localizadas informações sobre qual a periodicidade de realização e sobre a forma como esses dados seriam analisados e considerados em benefício do curso.

O PPP propõe ainda uma articulação entre o Plano de Desenvolvimento Institucional da universidade (PDI) que prevê inserção no contexto regional com a finalidade de contribuir para o desenvolvimento da reflexão e das potencialidades e dinamização da região e seu entorno - e, o curso de Psicologia através de atividades de pesquisa, ensino e extensão, nas quais o aluno estaria inserido em diferentes contextos que demandam análise, avaliação e intervenção, e em um ambiente propício para o desenvolvimento do senso crítico e da capacidade analítica para estabelecer relações entre fenômenos psicológicos e o contexto social. Contudo, no projeto não são indicadas quais disciplinas e estágios realizariam essa articulação de forma efetiva.

Pelo exposto, observa-se que a proposta deste PPP contempla os avanços da Psicologia no Brasil, expostos nas DCNP, entre os quais podemos destacar: quebra da hegemonia de áreas tradicionais (clínica, escola e trabalho), as quais enfatizavam a formação em áreas de avaliação psicológica e psicoterapias; quebra no padrão de ensino de uma psicologia que para ser científica, fazia-se neutra e abstinha-se da análise de aspectos da realidade social e de sua influência sobre os fenômenos psicológicos e sobre a subjetividade.

Do ponto de vista das DCNP, foi possível perceber a preocupação da instituição em pensar e planejar seu PPP a partir de uma formação mais abrangente, que valorizasse as peculiaridades da região em que está inserida e enfatizasse o trabalho em equipe inter e multidisciplinar.

Cabe ainda, destacar a importância de uma análise detalhada sobre a realidade do curso com finalidade de investigar os êxitos e as dificuldades encontradas por professores, coordenadores, alunos e outros atores (supervisores externos de estágios, instituições conveniadas, público-alvo do serviço de psicologia, entre outros) na implantação dessa proposta. Considerando que o primeiro processo seletivo ocorreu em 2009, a primeira turma deve estar concluindo a formação o que faz deste, um momento significativo para uma avaliação da proposta, quanto a sua real possibilidade de atender aos objetivos pretendidos. 


\section{CONSIDERAÇÕES FINAIS}

Algumas das críticas que a Psicologia recebe, no Brasil, referem-se às dificuldades dos psicólogos em trabalhar de forma integrada com profissionais de outras áreas e em considerar os diferentes contextos - social, cultural, econômico, político, histórico - nos quais o ser humano está inserido. As DCNP, nesse sentido, apresentam como alternativa o investimento em ambientes de aprendizagem e de formação profissional que privilegiem atuações inter e multiprofissionais e contemplem a análise da realidade dos vários contextos de atuação, refletindo e propondo intervenções que busquem responder às demandas, em cada um desses contextos, considerando a conjuntura.

A alternativa apresentada relaciona-se à discussão sobre currículo, pois este envolve toda a proposta de formação da área, desde os aspectos históricos que conduziram à regulamentação da profissão; à organização didático pedagógica direcionada aos conteúdos e sua dinâmica de desenvolvimento; à composição do corpo docente e sua qualificação; aos espaços para o desenvolvimento das atividades de ensino; dentre outras, que estão interrelacionadas no processo educativo.

Portanto, não basta a regulação através das DCNP e um PPP inovador, em conformidade com as mesmas se o currículo não for incorporado pela instituição e por seus atores, com todas as suas falhas e virtudes, possibilitando constantes movimentos de pensar e repensar sobre sua construção e seu produto; se de fato formam profissionais capazes de analisar e intervir sobre a realidade, nos vários contextos de atuação do psicólogo.

\section{REFERÊNCIAS}

ABDALLA, I. G.; BATISTA, S. H.; BATISTA, N. A. Desafios do ensino de psicologia clínica em cursos de psicologia. Psicologia: Ciência e Profissão, Brasília, v. 28, n. 4, p. 806819, 2008. Disponível em: <http://www.scielo.br/scielo.php?script=sci_arttext\&pid=S141498932008000400012\&lng= en\&nrm=iso> Acesso em: 02 jun. 2014.

ASSOCIAÇÃO BRASILEIRA DE ENSINO DE PSICOLOGIA. Parecer n. 403/62 do Conselho Federal de Educação, aprovado em 19 de Dezembro de 1962. Linha do tempo da Psicologia, ABEP, [2011]. Disponível em: <http://www.abepsi.org.br/portal/wpcontent/uploads/2011/07/1962-parecern403de19621.pdf> Acesso em: 02 jun. 2014.

BARDAGI, M. P. et al. Avaliação da formação e trajetória profissional na perspectiva de egressos de um curso de psicologia. Psicologia: Ciência e Profissão, Brasília, v. 28, n.2, p. 304-315, 2008. Disponível em: 
<http://www.scielo.br/scielo.php?script=sci_arttext\&pid=S1414-

98932008000200007\&lng=en\&nrm=iso> Acesso em: 02 jun. 2014.

BERNARDES, J. S. O debate atual sobre a formação em psicologia no Brasil análise de documentos de domínio público. Estudos e Pesquisas em Psicologia, Rio de Janeiro, v. 3, n. 2, jul. p. 127-134, 2003. Disponível em:

$<$ http://pepsic.bvsalud.org/scielo.php?script=sci_arttext\&pid=S1808-

$42812003000200009 \& \operatorname{lng}=$ t\&nrm=iso>. Acesso em: 02 jun. 2014.

A formação em Psicologia após 50 anos do Primeiro Currículo Nacional da

Psicologia: alguns desafios atuais. Psicologia: Ciência e Profissão, Brasília, v. 32, n. spe, p.

216-231, 2012. Disponível em:

<http://www.scielo.br/scielo.php?script=sci_arttext\&pid=S1414-

98932012000500016\&lng=en\&nrm=iso> Acesso em: 04 jun. 2014.

BRASIL. Decreto-lei no 9.092, de 26 de março de 1946. Amplia o regime didático das faculdades de filosofia e dá outras providências. Portal da Legislação, Palácio do Planalto, Presidência da República, 1946a. Disponível em:

<http://www.planalto.gov.br/ccivil_03/decreto-lei/1937-1946/Del9092.htm> Acesso em: 02 jun. 2014.

Ministério da Educação e Saúde. Portaria nº 272, de 13 de abril de 1946. Aprova instruções. Diário Oficial da União, 23/04/1946, Seção 1, Pg. 12. 1946b. Disponível em: <http://www.jusbrasil.com.br/diarios/2332379/pg-12-secao-1-diario-oficial-da-uniaodou-de-23-04-1946/pdfView> Acesso em: 02 jun. 2014.

Lei 4.119, de 27 de agosto de 1962. Dispõe sobre os cursos de formação em psicologia e regulamenta a profissão de psicólogo. Portal da Legislação, Palácio do Planalto, Presidência da República, 1962. Disponível em:

<http://www.planalto.gov.br/ccivil_03/leis/1950-1969/L4119.htm>. Acesso em: 02 jun. 2014.

Lei $\mathrm{n}^{\circ}$ 5.766, de 20 de dezembro de 1971. Cria o Conselho Federal e os Conselhos Regionais de Psicologia e dá outras providências. Portal da Legislação, Palácio do Planalto, Presidência da República, 1971. Disponível em:

<http://www.planalto.gov.br/Ccivil_03/LEIS/L5766.htm>. Acesso em: 02 jun. 2014.

Ministério da Educação. Parecer CNE/CES 1.314, de 7 de novembro de 2001. Diretrizes Curriculares para os cursos de graduação em Psicologia. Brasília, DF: Conselho Nacional de Educação, 2001. Disponível em:

<http://portal.mec.gov.br/cne/arquivos/pdf/CES1314.pdf>. Acesso em: 02 jun. 2014.

Ministério da Educação. Parecer CNE/CES No 62/2004. Diretrizes Curriculares Nacionais para os cursos de graduação em Psicologia. Brasília, DF: Conselho Nacional de Educação, 2004a. Disponível em:

<http://portal.mec.gov.br/index.php?option=com_content\&id=12991:diretrizes -curricularescursos-de-graduacao> Acesso em: 08 jun. 2014. 
BRASIL. Ministério da Educação. Resolução CNE/CES No 8, de 07 de maio de 2004. Diretrizes Curriculares Nacionais para os cursos de graduação em Psicologia. Brasília, DF: Conselho Nacional de Educação, 2004b. Disponível em:

$<$ http://portal.mec.gov.br/index.php?option=com_content \&id=12991:diretrizes-curricularescursos-de-graduacao> Acesso em: 08 jun. 2014.

Ministério da Educação. Parecer CNE/CES No 338, de 12 de novembro de 2009. Aprecia a Indicação CNE/CES $n^{\circ}$ 2/2007, que propõe a alteração do art. 13 da Resolução CNE/CES $n^{\circ}$ 8, de 7 de maio de 2004, que institui as Diretrizes Curriculares Nacionais para os cursos de graduação em Psicologia. Brasília, DF: Conselho Nacional de Educação, 2009. Disponível em:

<http://portal.mec.gov.br/index.php?option=com_content\&id=12991:diretrizes-curricularescursos-de-graduacao> Acesso em: 08 jun. 2014.

Ministério da Educação. Resolução CNE/CES No 5 de 15 de março de 2011.

Diretrizes Curriculares Nacionais para os cursos de graduação em Psicologia, estabelecendo normas para o projeto pedagógico complementar para a Formação de Professores de Psicologia. Brasília, DF: Conselho Nacional de Educação, 2011. Disponível em: $<$ http://portal.mec.gov.br/index.php?option=com_content\&id=12991:diretrizes-curricularescursos-de-graduacao> Acesso em: 08 jun. 2014.

BRASILEIRO, T. S. A.; SOUZA, M. P. R. Psicologia, diretrizes curriculares e processos educativos na Amazônia: um estudo da formação de psicólogos. Revista da Associação Brasileira de Psicologia Escolar e Educacional, Campinas, v. 14, n. 1, p. 105-120, Jun. 2010. Disponível em: <http://www.scielo.br/scielo.php?script=sci_arttext\&pid=S1413$85572010000100012 \& \operatorname{lng}=$ en\&nrm=iso> Acesso em: 15 jun. 2014.

CONSELHO FEDERAL DE PSICOLOGIA. Contribuições do Conselho Federal de Psicologia à Discussão sobre a Formação da (o) psicóloga (o). Brasília, Agosto, 2013. 1. ed. XV Plenário - Gestão 2011/2013. Disponível em:

$<$ http://site.cfp.org.br/publicacao/contribuicoes-do-conselho-federal-de-psicologia-adiscussao-sobre-a-formacao-dao-psicologao/> Acesso em: 08 jun. 2014.

CONSELHO REGIONAL DE PSICOLOGIA DA 6a REGIÃO (Org.) Exposição 50 anos da psicologia no Brasil: A História da psicologia no Brasil. Conselho Regional de Psicologia da $6^{a}$ Região. São Paulo: CRPSP, 2011. Disponível em:

<http://www.crpsp.org.br/portal/comunicacao/pdf/catalogo50anos.pdf >. Acesso em: 09 jun. 2014.

DALTRO, M. et al. Internato em Psicologia: uma prática Interdisciplinar assistida. Revista Psicologia, Diversidade e Saúde, Salvador, v. 1, n. 2, p. 64-80, 2013. Disponível em: <http://www.bahiana.edu.br/revistas> Acesso em: 11 jun. 2014.

FERES-CARNEIRO, T. Memórias do Curso de Pós-graduação em Psicologia da PUC - Rio: comemorando seus 40 anos. Psicologia Clínica, Rio de Janeiro, v. 19, n. 1, p. 217-225, 2007. Disponível em: <http://www.scielo.br/scielo.php?script=sci_arttext\&pid=S0103-

56652007000100016\&lng=en\&nrm=iso> Acesso em: 08 jun. 2014. 
FERREIRA NETO, J. L.; PENNA, L. M. D. Ética, clínica e diretrizes: a formação do psicólogo em tempos de avaliação de cursos. Psicologia em Estudo, Maringá, v. 11, n. 2, p. 381-390, Ago. 2006. Disponível em:

<http://www.scielo.br/scielo.php?script=sci_arttext\&pid=S1413-

$73722006000200017 \& \operatorname{lng}=$ en\&nrm=iso> Acesso em: 04 jun. 2014.

LISBOA, F. S.; BARBOSA, A. J. G. Formação em Psicologia no Brasil: um perfil dos cursos de graduação. Psicologia: Ciência e Profissão, Brasília, v. 29, n. 4, p. 718-737, 2009.

Disponível em: <http://www.scielo.br/scielo.php?script=sci_arttext\&pid=S141498932009000400006\&lng=en\&nrm=iso>. Acesso em: 15 jun. 2014.

LOPES, S. R. A.; LIMA, J. M. F. A parceria universidade-instituição de saúde e sua importância na formação do aluno de graduação em psicologia. Psicologia: Teoria e Prática, São Paulo, v. 14, n. 3, p. 111-122, 2012. Disponível em:

<http://www.redalyc.org/articulo.oa?id=193824911009>. Acesso em: 8 jun. 2014.

MASSIMI, M. História da psicologia brasileira: da época colonial até 1934. São Paulo: EPU, 1990.

PENNA, A. G. História da psicologia no Rio de Janeiro. Rio de Janeiro: Imago, 1992.

PEREIRA, F. M.; PEREIRA NETO, A. O psicólogo no Brasil: notas sobre seu processo de profissionalização. Psicologia em Estudo, Maringá, v. 8, n. 2, p. 19-27, Dez. 2003.

Disponível em: <http://www.scielo.br/scielo.php?script=sci_arttext\&pid=S1413-

$73722003000200003 \& \operatorname{lng}=$ en\&nrm=iso $>$ Acesso em: 17 jun. 2014.

POPPE, A. R. S.; BATISTA, S. H. S. S. Formação em Psicologia no contexto das diretrizes curriculares nacionais: uma discussão sobre os cenários da prática em saúde. Psicologia:

Ciência e Profissão, Brasília, v. 32, n. 4, p. 986-999, 2012. Disponível em:

$<$ http://www.scielo.br/scielo.php?script=sci_arttext\&pid=S1414-98932012000400016

\&lng=en\&nrm=iso> Acesso em: 02 jun. 2014.

RONZANI, T. M.; RODRIGUES, M. C. O Psicólogo na Atenção Primária à Saúde:

Contribuições, Desafios e Redirecionamentos. Psicologia: Ciência e Profissão. São Paulo, v. 26, n 1, p. 132-143, 2006. Disponível em:

<http://www.scielo.br/scielo.php?script=sci_arttext\&pid=S1414-

98932006000100012\&lng=en\&nrm=iso> Acesso em: 28 jun. 2014.

SACRISTAN, J. G. O currículo: uma reflexão sobre a prática. 3. ed. Porto Alegre: ArtMed, 2000.

SILVA, T. T. Dr. Nietzsche, curriculista - com uma pequena ajuda do professor Deleuze. In: $24^{a}$ REUNIÃO ANUAL DA ASSOCIAÇÃO NACIONAL DE PÓS-GRADUAÇÃO E PESQUISA EM EDUCAÇÃo (ANPED), 2001. Caxambu. GT 12 Currículo. Caxambu: ANPED, 2001. Disponível em:

<http://24reuniao.anped.org.br/tp1.htm\#gt12> Acesso em: 08 jun. 2014. 
SOARES, A. R. A Psicologia no Brasil. Psicologia: Ciência e Profissão, Brasília, 2010, 30 (núm. esp.), p. 8-41. Disponível em:

<http://www.scielo.br/pdf/pcp/v30nspe/v30speca02.pdf>. Acesso em: 15 jun. 2014.

VILELA, A. M. J. História da Psicologia no Brasil: uma narrativa por meio de seu ensino. Psicologia: Ciência e Profissão, Brasília, v. 32, n. spe, p. 28-43, 2012. Disponível em: $<$ http://www.scielo.br/scielo.php?script=sci_arttext\&pid=S1414-98932012000500004\&lng= pt\&nrm=iso>. Acesso em: 10 jun. 2014.

YAMAMOTO, O. H. A LDB e a Psicologia. Psicologia: Ciência e Profissão, Brasília, v. 20, n. 4, p. 30-37, Dez. 2000. Disponível em:

$<$ http://www.scielo.br/scielo.php?script=sci_arttext\&pid=S1414-

98932000000400004\&lng=en\&nrm=iso>. Acesso em: 24 jun. 2014.

ZURBA, M. C. A história do ingresso das práticas psicológicas na saúde pública brasileira e algumas consequências epistemológicas. Memorandum, Belo Horizonte: UFMG; Ribeirão Preto: USP, 20, 105-122, abr. 2011. Disponível em:

<http://www.fafich.ufmg.br/memorandum/a20/zurba01> Acesso em: 02 jun. 2014. 